\title{
VOLTAGE TRANSIENT MEASUREMENTS IN A DISTRIBUTION NETWORK AND SEQUENCE OF RELAY EVENTS ASSOCIATED TO LIGHTNING STROKES DETECTED BY LLS
}

\author{
A. Borghetti ${ }^{1}$, F. Napolitano ${ }^{1}$, C.A. Nucci ${ }^{1}$, M. Paolone ${ }^{1}$, M. Bernardi ${ }^{2}$ \\ ${ }^{1}$ Dept. of Electrical Engineering, University of Bologna, viale Risorgimento 2, 40136 Bologna, Italy. \\ ${ }^{2}$ CESI, via Rubattino 54, 20134 Milano, Italy
}

\begin{abstract}
A two-year experimental campaign on lightning-originated disturbances carried out in an Italian rural region characterized by a high ground flash density (4 flashes $/ \mathrm{km}^{2} / \mathrm{yr}$ ) has provided a set of voltage transient measurements in a medium voltage (MV) feeder that are clearly correlated with both specific events detected by the Italian lightning location system (LLS) CESI-SIRF and sequences of relay operations. The paper describes the sequence of relay events, reports the data of the correlated LLS-detected stroke and presents the corresponding voltage transients recorded at three different busses of the MV feeder.
\end{abstract}

\section{INTRODUCTION}

An important issue for lightning protection/insulation coordination of overhead lines is the distinction between lightning caused faults from those due to other phenomena in general associated with thunderstorms, such as wind, rain, hail and trembling trees, which call for different countermeasures. Indeed, it is not uncommon that several outages and faults causing reclosing operations during thunderstorms are not really due to lightning, as Darveniza and Uman have observed in [1] as a result of a University of Florida's research project carried out at the end of the $70 \mathrm{~s}$. That research project dealt with the correlation between ground flash data, obtained by several sources (flash counters, direction-finder based LLS, electric and magnetic fields recording systems, television lightning monitors), measurements of surge currents discharged through arresters [2] and distribution system records of circuit breaker operations. Other experimental projects have been carried out for the same purposes. For example, in the $80 \mathrm{~s}$, as a part of a an U.S. EPRI research project on the characteristics of lightning surges on distribution lines, an instrumentation called coincident lightning events detector (CLED) was developed and installed at some substations in Florida [3,4]. The CLED used a modified flash counter to sense when lightning occurs and a time-tagged information obtained from the distribution substation supervisory control and data acquisition (SCADA) system to determine if a subsequent circuit breaker operation was caused by lightning, taking into account that a distribution circuit breaker takes 4 to 6 cycles to trip after fault initiation. The modified flash counter used a 2-m antenna able to be triggered by the voltages induced by lightning events in the estimated range of $9.6 \mathrm{~km}$, approximately the same size as the substation service area. As more sophisticated LLSs have been developed since the end of the 70 s, their use has been proposed for the correlation between lightning events and faults in distribution networks [5$10]$.

However, due to the uncertainties associated with the data provided by LLS and the complexity of MV networks and their protections, the reliable correlation between faults and specific LLS-detected events is still an open issue and represents the motivation for the recent experimental campaign on lightning-originated disturbances in an Italian rural region characterized by a high ground flash density (4 flashes $/ \mathrm{km}^{2} / \mathrm{yr}$ ).

As described in [9,11-13], three measurement units able to record a-periodic voltage transients characterized by frequency content up to $4 \mathrm{MHz}$ have been installed in one $20-\mathrm{km}$ long MV feeder mainly composed by threephase overhead lines. The compensated-neutral grounded feeder is protected by both overcurrent and zero-sequence relays. The relay operations are monitored by a sequence of events recorder with a 10-ms sampling time.

During a two-year (2007-2008) period, a set of voltage transient measurements, clearly correlated both with specific events detected by the Italian lightning location system (LLS) CESI-SIRF and with sequences of relay operations, have been collected.

The paper describes the sequence of relay events, reports the data of the correlated LLS-detected stroke and presents the corresponding voltage transients. 


\section{VOLTAGE TRANSIENTS MEASUREMENTS AND SEQUENCE OF RELAY INTERVENTIONS CORRELATED WITH LLS DETECTED STROKES}

This section presents the analysis of the voltage transients and sequence of relay events due to the lightning strokes of 6 of the flashes detected by the LLS (indicated in the following with no. 15714, 62676, 64244, 4970, 1169, and 44074). Fig. 1 shows the LLS-estimated stroke locations with respect to the feeder and their 50\% error ellipse.

In the following subsections, for each flash, we report the sequence of relays interventions as recorded by distribution data acquisition system and the voltage transients recorded by the three measurement units.

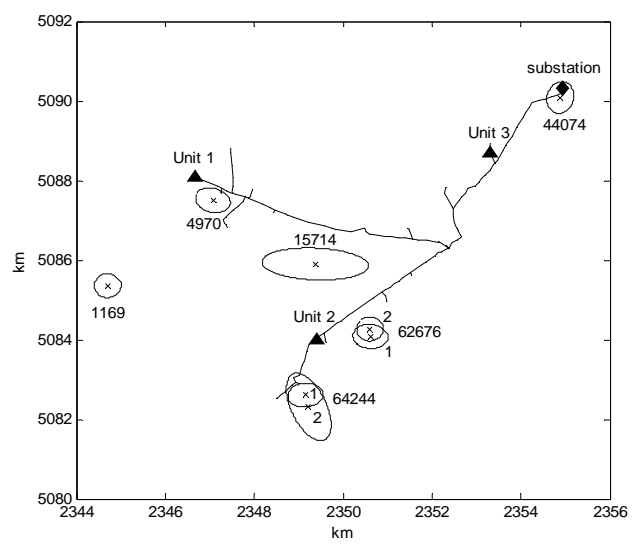

Fig. 1 LLS estimated stroke locations relevant to 6 flashes associated with relay sequence of events and the corresponding $50 \%$ error ellipses. The numbers in the $\mathrm{x}$ and $\mathrm{y}$ axes reports the coordinates using the cylindrical projection called Gauss-Boaga traditionally used in Italian maps.

\subsection{Flash 15714 (May 15, 2007)}

The event 15714-1 was detected by the LLS on May 15th, 2007 at 14:30:20.627983052 (standard time UTC) as a first positive stroke characterized by a $8.7 \mathrm{kA}$ current peak value. As shown in Fig. 1, the major and minor axes of the $50 \%$ error ellipse are equal to $1200 \mathrm{~m}$ and $400 \mathrm{~m}$, respectively.

Fig. 2 shows the voltage transients recorded by Unit 1 as a result of a triggering signal at $9.8 \mu$ s after the LLS detected event. The other two units did not record any transient. The relay monitoring system recorded the activation of the overcurrent relay 51 at 14:30:20.63, which was deactivated without tripping $110 \mathrm{~ms}$ after its activation.

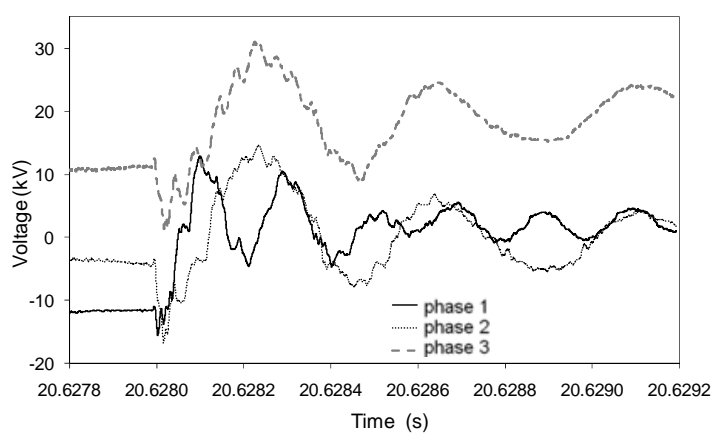

Fig. 2 Voltage transients correlated to LLS event 1514-1 recorded at Unit 1 (moving average in a $5 \mu$ s period).

\section{$2.2 \quad$ Flash 62676 (June 15, 2007)}

The event 62676-1 was detected by the LLS on June 15th, 2007 at 16:30:20.511131173 as a negative first stroke characterized by a $10.3 \mathrm{kA}$ current peak value. As shown in Fig. 1, the major and minor axes of the 50\% error ellipse are equal to $400 \mathrm{~m}$ and $300 \mathrm{~m}$, respectively.

Fig. 3 shows the voltage transients recorded at the three measurement units triggered with a delay equal to $40.6 \mu \mathrm{s}$ (Unit 1), to $2.8 \mu \mathrm{s}$ (Unit 2, the nearest to the estimated stroke location) and to $18.2 \mu$ s (Unit 3, Venus), after the LLS detected event. The relay monitoring system recorded the activation of the overcurrent relay 51 at 16:30:20.54.

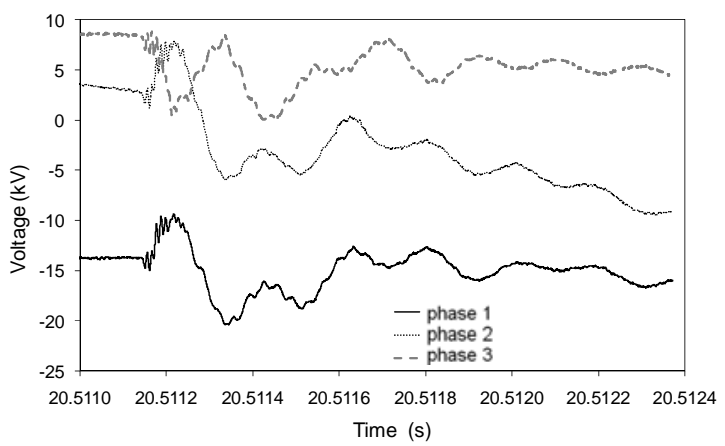

a)

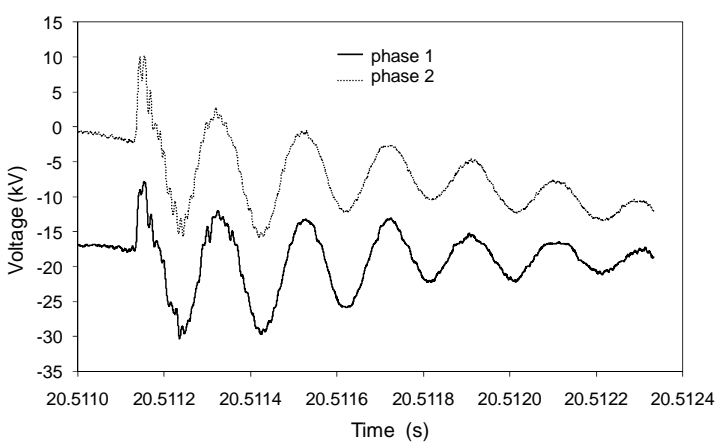




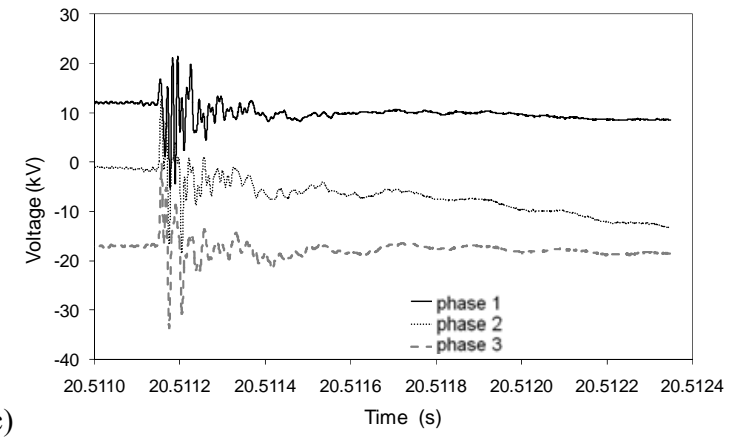

Fig. 3 Recorded voltage transients correlated with LLS event 62676-1: a) Unit 1, b) Unit 2, c) Unit 3. Phase 3 was not recorded at Unit 2 (moving average in a $5 \mu$ s period).

Almost $50 \mathrm{~ms}$ after the first event (at 16:30:20.566098022), the LLS detected a second negative stroke (Event 62676-2) of $11.5 \mathrm{kA}$ current peak. The estimated stroke location and 50\% error ellipse are also shown in Fig. 1 (both major and minor axes are equal to $300 \mathrm{~m}$ ).

Fig. 4 shows the resulting voltage transients recorded by the three units triggered after a delay equal to $31.6 \mu \mathrm{s}$ (Unit 1), to $3.6 \mu$ s (Unit 2) and to $15.7 \mu$ s (Unit 3). The transient recorded at Unit 2 clearly shows the fault in a phase and, indeed, the relay monitoring systems recorded the activation of $\mathrm{AC}$ directional overcurrent relay 67 at $16: 30: 20.57$.

a)
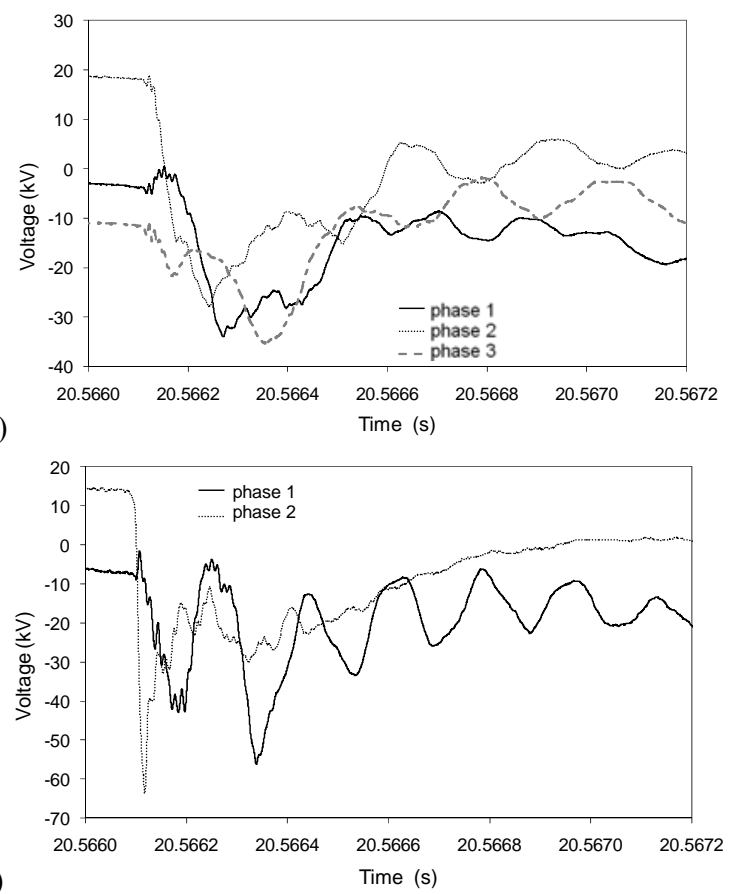

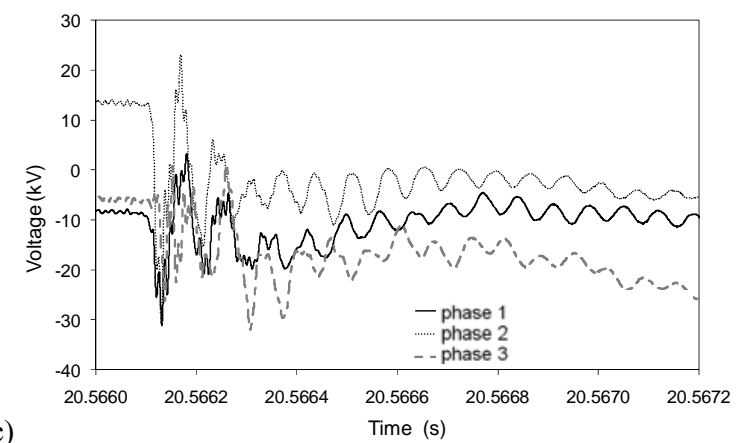

Fig. 4 Recorded voltage transients correlated with LLS event 62676-2: a) Unit 1, b) Unit 2, c) Unit 3. Phase 3 was not recorded at Unit 2 (moving average in a $5 \mu$ s period).

The relay trips after $90 \mathrm{~ms}$ and the ensuing circuit breaker opening at the substation caused the voltage transients recorded at Unit 3 (the nearest to the substation) and, also, at Unit 1, as shown in Fig. 5. After $470 \mathrm{~ms}$ the circuit breaker re-closing maneuver causes the recorded voltage transients shown in Fig. 6. The voltage transient recorded at Unit 3 shows that one of the circuit breaker poles re-closes with a delay of about $1 / 3$ of ms after the others.
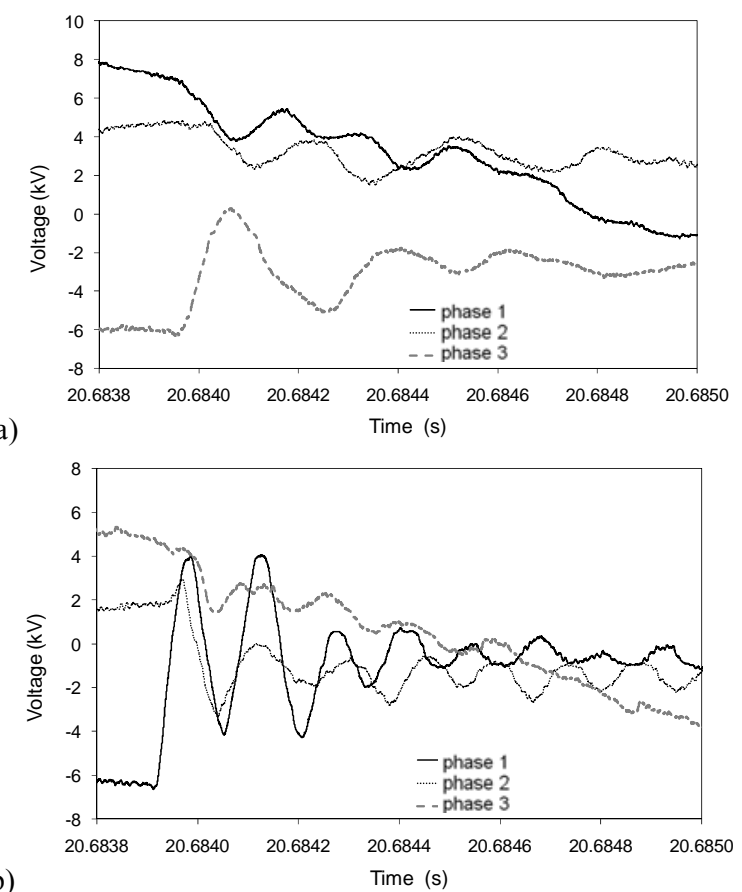

Fig. 5 Recorded voltage transients correlated with the opening of the circuit breaker to clear the fault caused by flash 62676: a) Unit 1, b) Unit 3. Unit 2 was not triggered (moving average in a $5 \mu$ s period) 


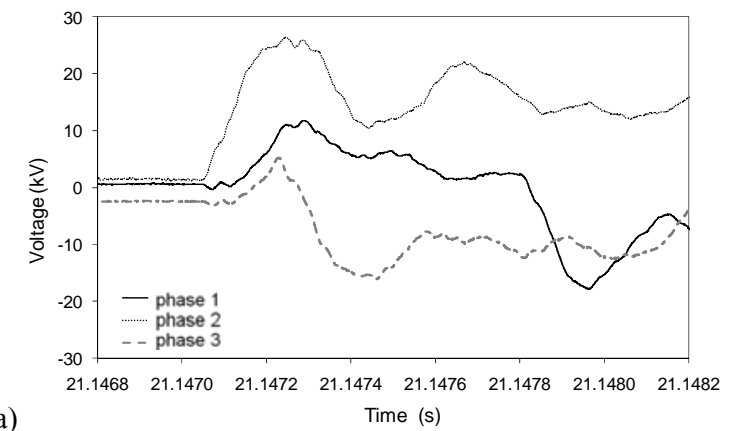

a)

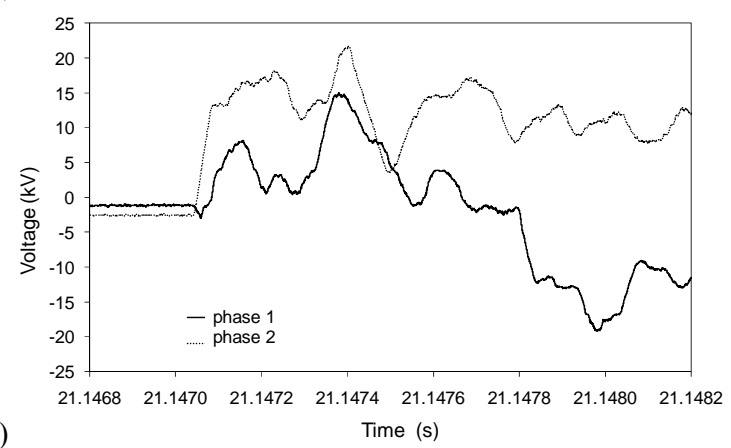

b)

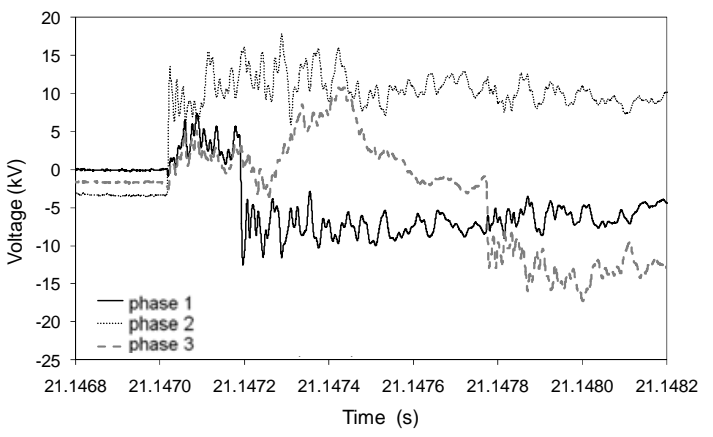

Fig. 6 Recorded voltage transients correlated to the circuit breaker reclosure after the trip of Fig. 5: a) Unit 1, b) Unit 2, c) Unit 3. Phase 3 was not recorded at Unit 2 (moving average in a $5 \mu$ s period).

\subsection{Flash 64244 (June 15, 2007)}

The event 64244-1 was detected by the LLS on June 15th, 2007 at 16:41:49.626720476 as a first negative stroke characterized by a $11.2 \mathrm{kA}$ current peak value. As shown in Fig. 1, the major and minor axes of the $50 \%$ error ellipse are equal to $400 \mathrm{~m}$ and $300 \mathrm{~m}$, respectively.

Fig. 7 shows the voltage transients recorded at the three measurement units. Unit 1 and Unit 3 are triggered after a delay equal to $42.8 \mu \mathrm{s}$ and $29.9 \mu \mathrm{s}$, respectively. Unit 2 triggered $37.676 \mu$ s before the time in which the event was detected by the LLS detected, probably due to the leader induced effects. The transient recorded at Unit 2 shows a very high overvoltage (larger than $100 \mathrm{kV}$ line to ground) that causes a fault. Indeed, the relay monitoring system recorded the activation of both the directional overcurrent relay 67 and the overcurrent relay
51 at 16:41:49.64 and at 16:41:49.65, respectively.

With a delay of $43.9 \mathrm{~ms}$ after the first event, at 16:41:49.670654962, the LLS detected a second negative stroke of the same flash (event 64244-2) of $10.4 \mathrm{kA}$ current peak, the estimated stroke location and $50 \%$ error ellipse of which are shown in Fig. 1 (major and minor axes are equal to $900 \mathrm{~m}$ and to $400 \mathrm{~m}$, respectively).

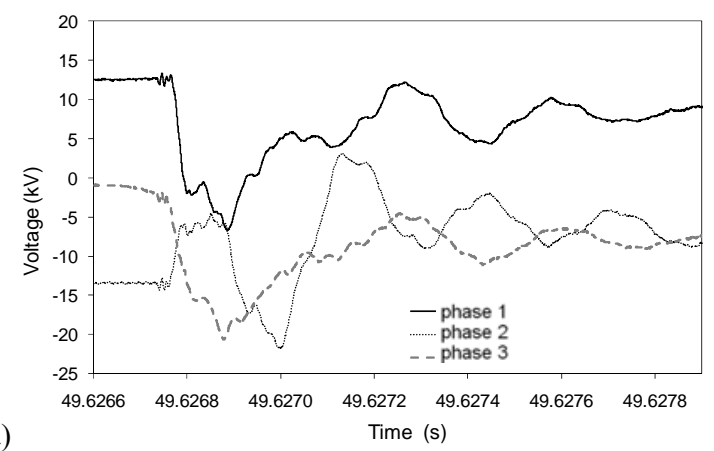

a)
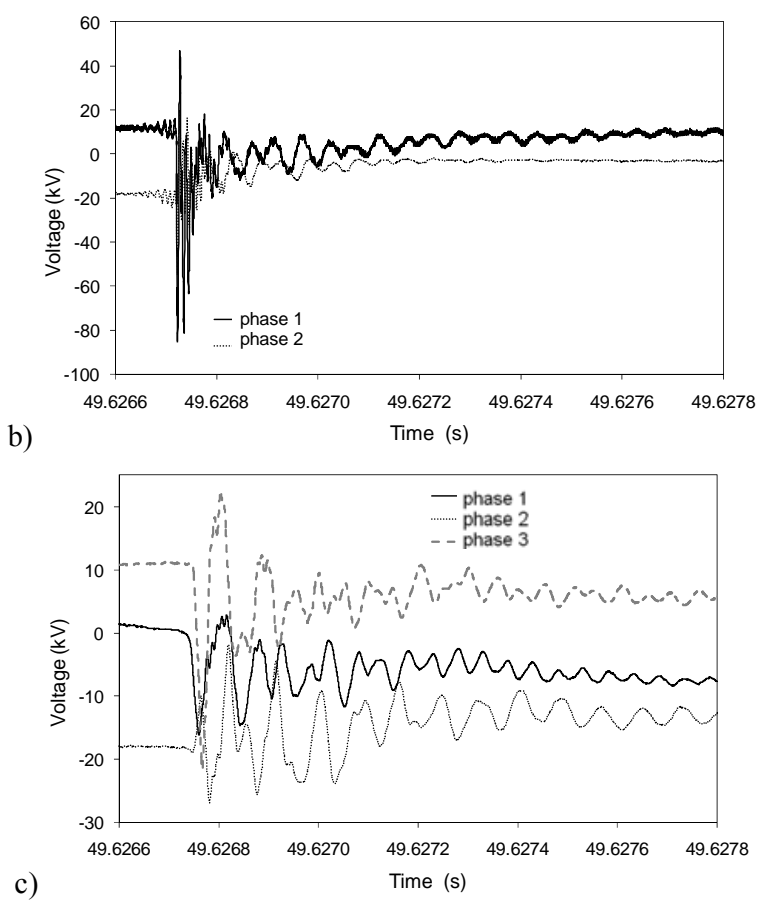

Fig. 7 Recorded voltage transients correlated with LLS event 64244-1: a) Unit 1, b) Unit 2, c) Unit 3. Phase 3 was not recorded at Unit 2 (moving average in a $5 \mu$ s period except for the case of Unit 2).

Fig. 8 shows the corresponding voltage transients recorded at the three measurement units: Unit 1 and Unit 3 triggered after a delay equal to $23.7 \mu \mathrm{s}$ and $43.5 \mu \mathrm{s}$, respectively; whilst Unit 2 triggered $0.6 \mu$ s before the time tag of the LLS event. The transient recorded at Unit 2 shows the induced voltages on faulted conductors. 


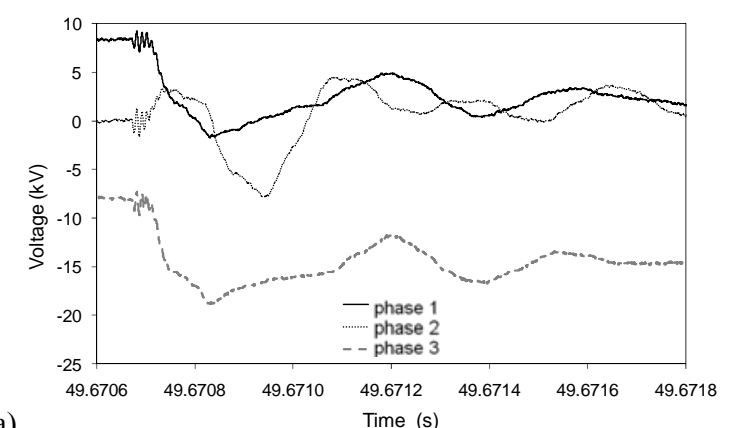

a)

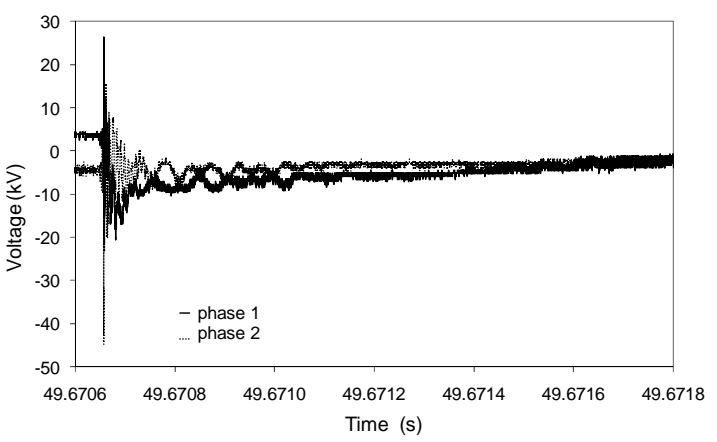

b)

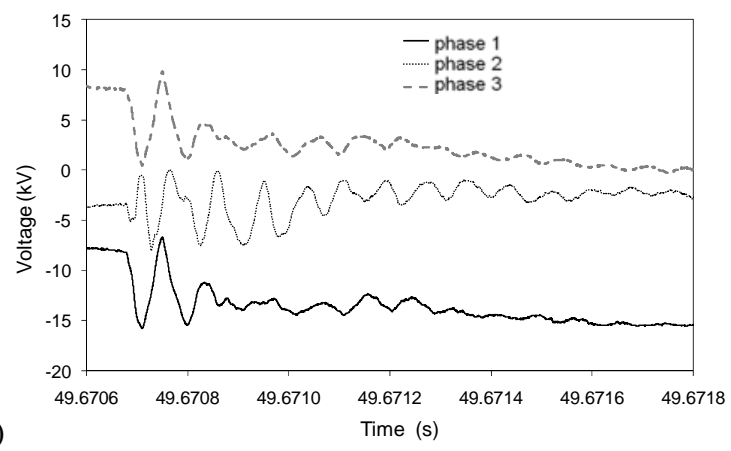

Fig. 8 Recorded voltage transients correlated with LLS event 64244-2: a) Unit 1, b) Unit 2, c) Unit 3. Phase 3 was not recorded at Unit 2. (Moving average in a $5 \mu$ s period except for the case of Unit 2)

After $59 \mathrm{~ms}$, the directional relay eventually trips and the ensuing opening of the circuit breaker caused the voltage transients at Unit 3 (the nearest to the substation) shown in Fig. 9.

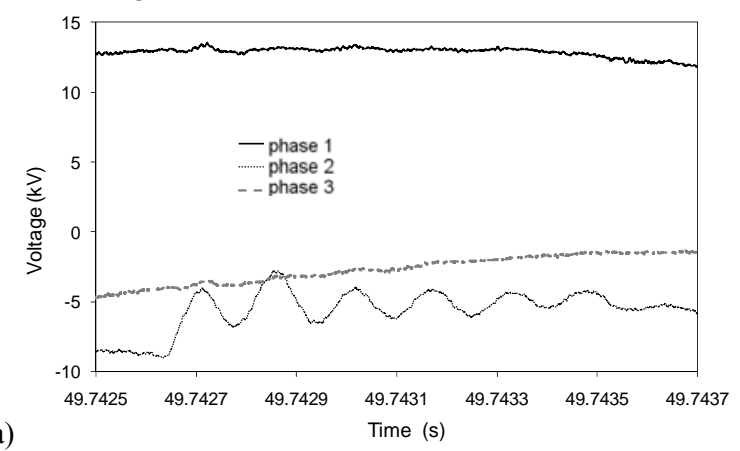

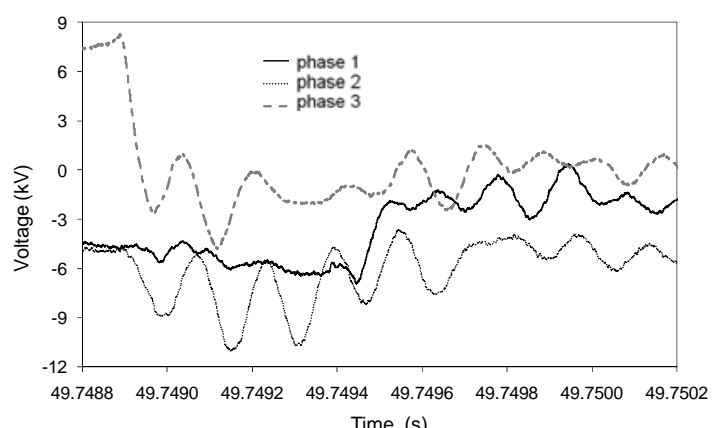

b)

Time (s)

Fig. 9 Voltage transients correlated with the opening of the circuit breaker to clear the fault caused by flash 64244 recorded at Unit 3: a) first pole opening, b) second and third pole opening. (Moving average in a $5 \mu$ s period)

After $410 \mathrm{~ms}$ the circuit breaker re-closing maneuver causes the recorded voltage transients shown in Fig. 10.

a)
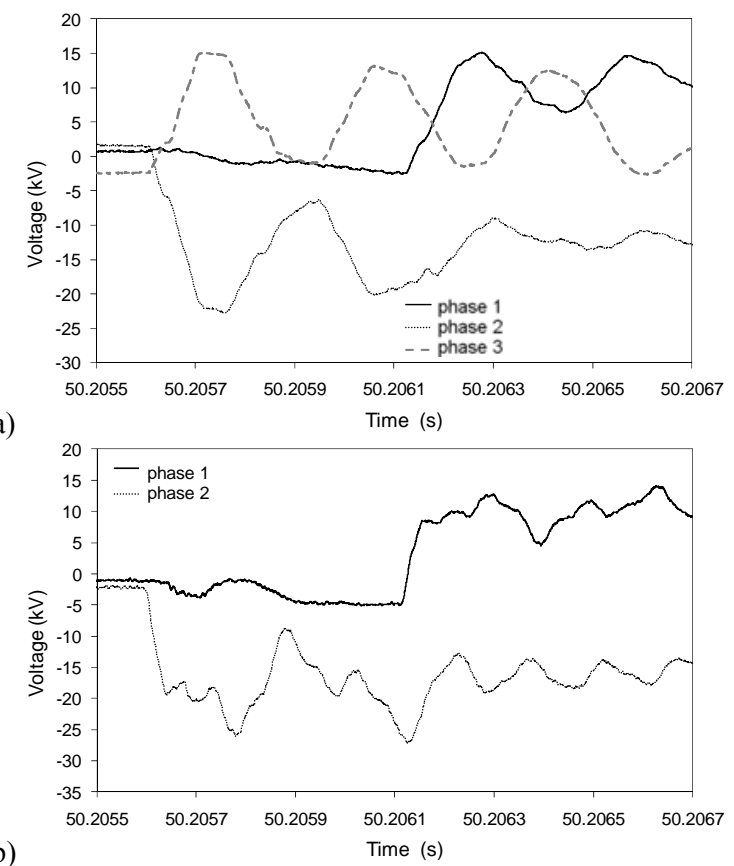


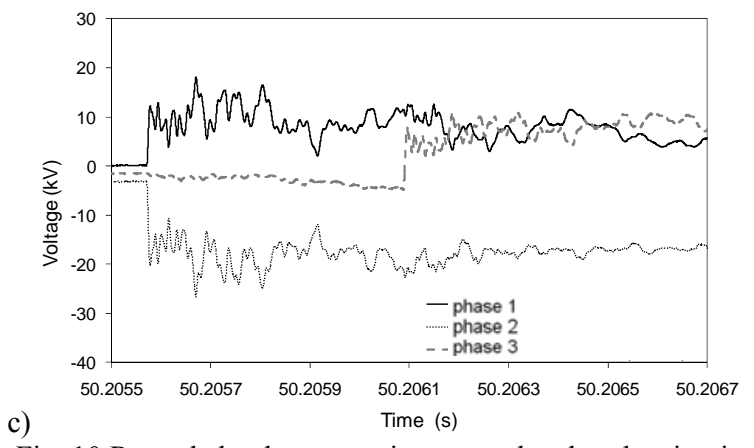

Fig. 10 Recorded voltage transients correlated to the circuit breaker reclosure after the trip of Fig. 9: a) Unit 1, b) Unit 2, c) Unit 3. Phase 3 was not recorded at Unit 2 (moving average in a $5 \mu$ s period).

\section{$2.4 \quad$ Flash 4970 (August 9, 2007)}

The event 4970-1 has been detected by the LLS on August 9th, 2007 at 02:31:49.484531417 as a first negative stroke characterized by a $15.9 \mathrm{kA}$ current peak value. As shown in Fig. 1, the stroke location is close to Unit 1 and the major and minor axes of the $50 \%$ error ellipse are equal to $400 \mathrm{~m}$ and $300 \mathrm{~m}$, respectively.

Fig. 11 shows the voltage transients recorded at the three measurement units. Unit 2 and Unit 3 were triggered after a delay with respect to the LLS event equal to $68.5 \mu \mathrm{s}$ and $50.0 \mu \mathrm{s}$, respectively. Unit 1 was triggered $89.5 \mu \mathrm{s}$ before the time in which the event was detected by the LLS. The transient recorded at Unit 2 shows line-to-ground overvoltages well above $60 \mathrm{kV}$ (at which value the data acquisition board saturated) that caused a fault. Indeed, the relay monitoring system recorded the activation of both the overcurrent relay 51 and the directional overcurrent relay 67 at 02:31:49.49 and at 02:31:49.51, respectively. The consequential opening of the circuit breaker cleared the fault and Fig. 12 shows the recorded voltage transients associated with the circuit breaker re-closure triggered at 02:31:50.981.

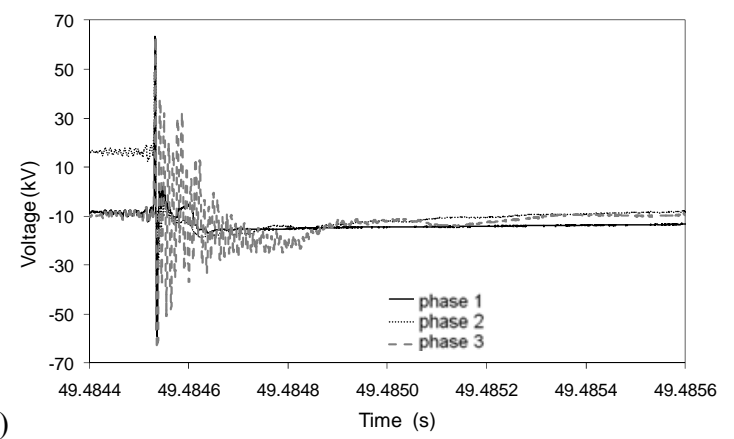

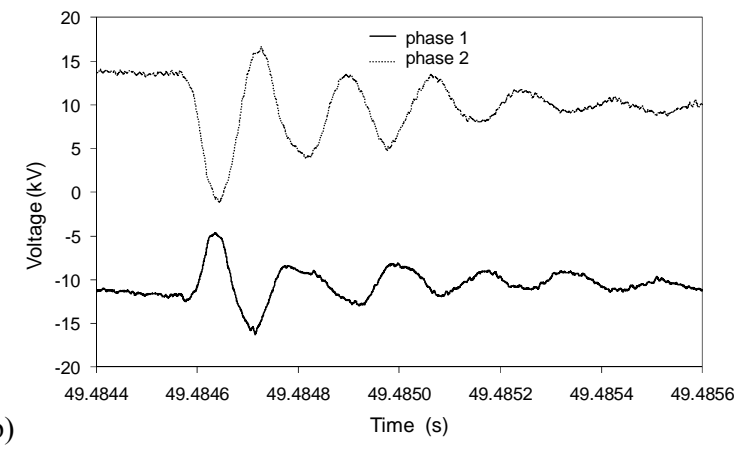

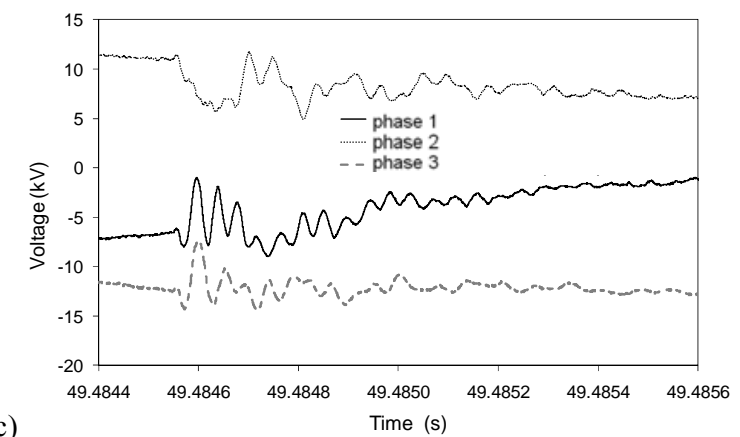

Fig. 11 Recorded voltage transients correlated with LLS event 4970-1: a) Unit 1, b) Unit 2, c) Unit 3. Phase 3 was not recorded at Unit 2 (moving average in a $5 \mu$ s period except for the case of Unit 1).
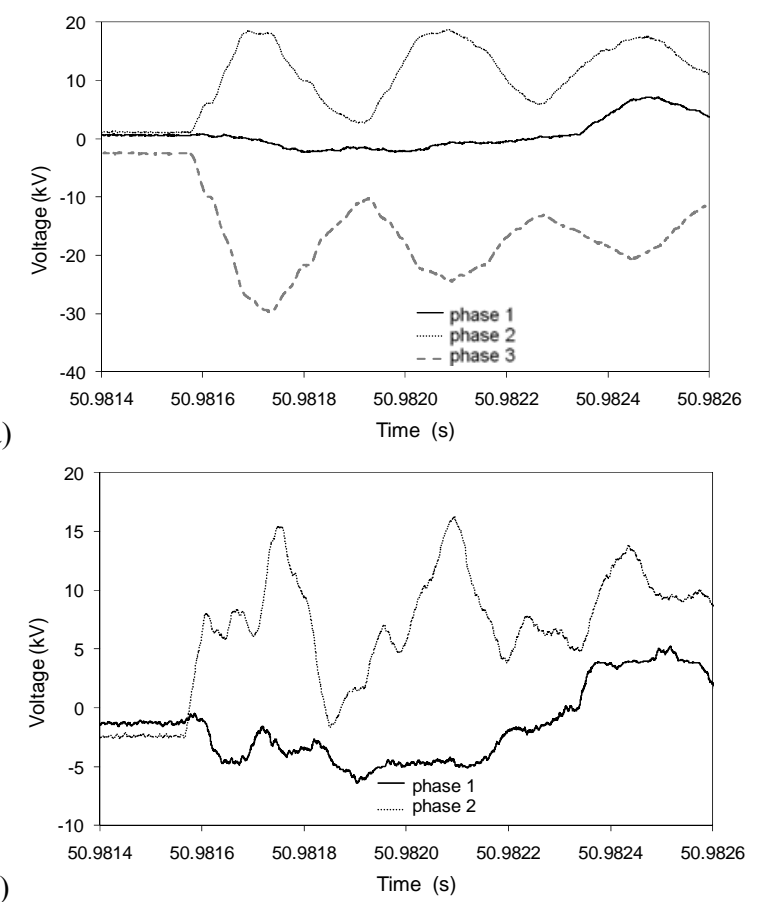


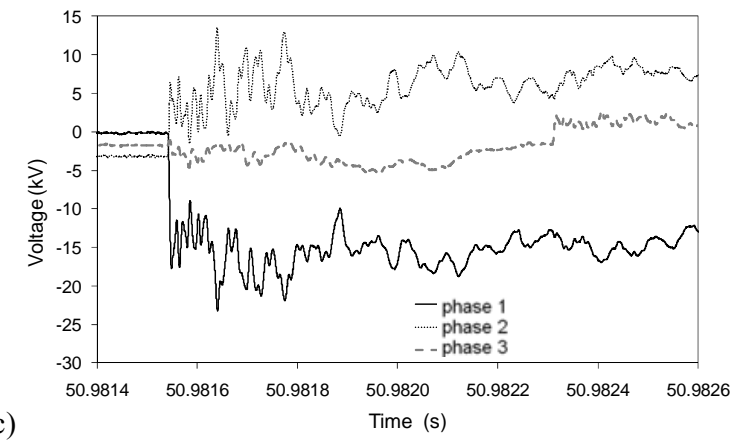

Fig. 12 Recorded voltage transients correlated to the circuit breaker reclosure after the trip due to LLS-detected event 4970-

1: a) Unit 1, b) Unit 2, c) Unit 3. Phase 3 was not recorded at Unit 2 (moving average in a $5 \mu$ s period).

\section{$2.5 \quad$ Flash 1169 (May 23, 2008)}

The event 1169-1 was detected by the LLS on May 23rd, 2008 at 04:54:04.831727601 as a first positive stroke characterized by a $33.8 \mathrm{kA}$ current peak value. Fig. 1 shows the stroke location estimated by the LLS together with the $50 \%$ error ellipse (major and minor axes are equal to $300 \mathrm{~m}$ ).

Fig. 13 shows the voltage transients recorded at the three measurement units, triggered with a delay equal to $19.80 \mu$ s (Unit 1), $101.9 \mu$ s (Unit 2) and $39.0 \mu$ s (Unit 3). Due to the stroke location, the highest overvoltages are recorded by Unit 1 and Unit 2 . The relays detect a fault in the feeder. Fig. 14 shows the voltage transients at Unit 3 associated to the opening of the circuit breaker triggered at 06:54:05.082 and to the re-closure triggered at 06:54:05.431.

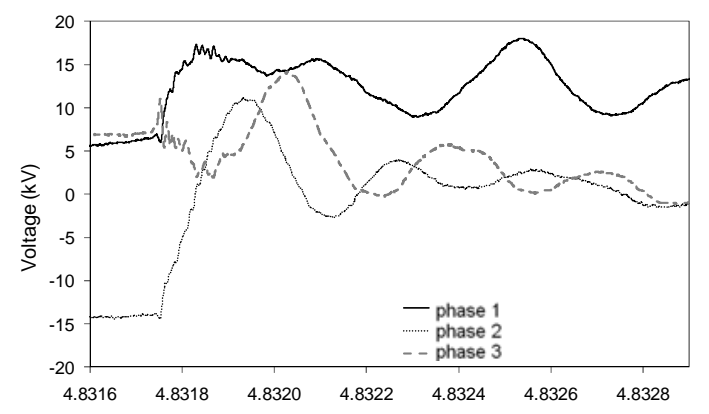

a)

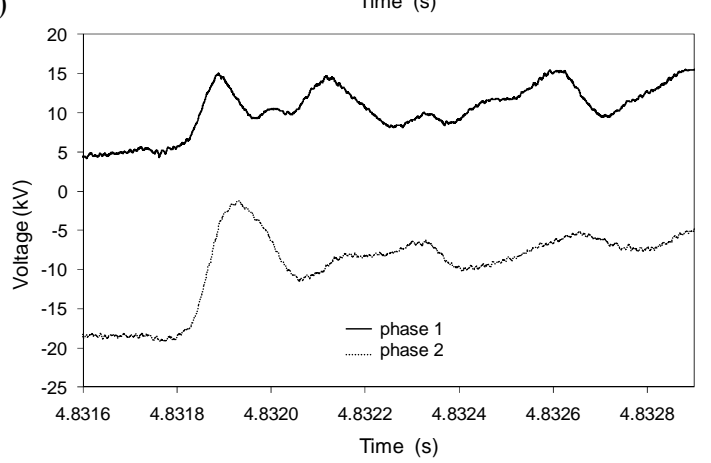

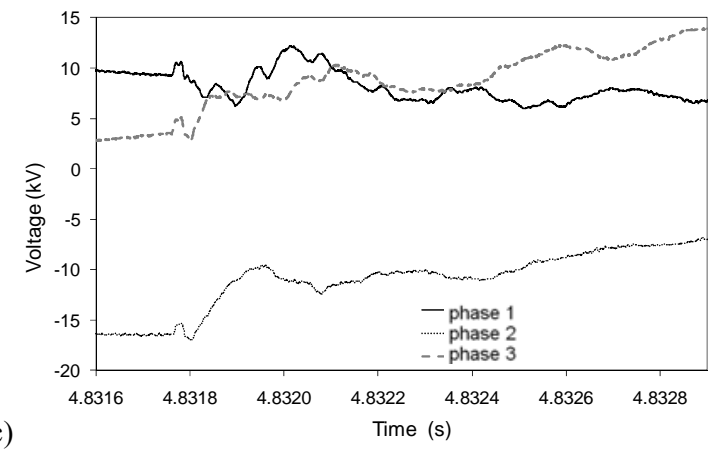

Fig. 13 Recorded voltage transients correlated with LLS event 1169-1: a) Unit 1, b) Unit 2, c) Unit 3. Phase 3 was not recorded at Unit 2 (moving average in a $5 \mu$ s period except for the case of Unit 1).

a)
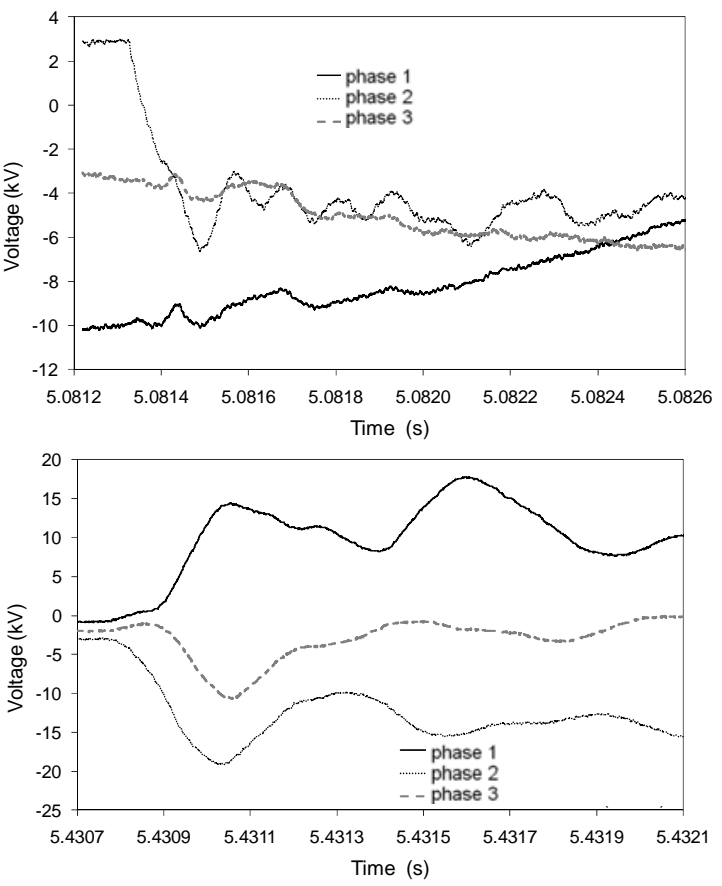

Fig. 14 Recorded voltage transients at Unit 3 correlated to the circuit breaker maneuvers due to LLS-detected event 1169-1: a) opening, b) re-closure (moving average in a $5 \mu$ s period).

\section{$2.6 \quad$ Flash 44074 (June 11, 2008)}

The event 44074-1 was detected by the LLS on June 11th, 2008 at 15:32:56.060838753 as a first positive stroke characterized by a $81.2 \mathrm{kA}$ current peak value. The stroke location estimated by the LLS is shown in Fig. 1 together with the $50 \%$ error ellipse (major and minor axes are equal to $400 \mathrm{~m}$ and $300 \mathrm{~m}$, respectively).

Fig. 15 shows the voltage transients recorded at Unit 2 and Unit 3, triggered with a delay equal to $35.4 \mu$ s and $14.2 \mu \mathrm{s}$, respectively. As expected, the largest overvoltages are recorded by Unit 3 . The relay monitoring system recorded the activation of the overcurrent relay 51 at 15:32:56.08, which is deactivated 
without tripping after $30 \mathrm{~ms}$.

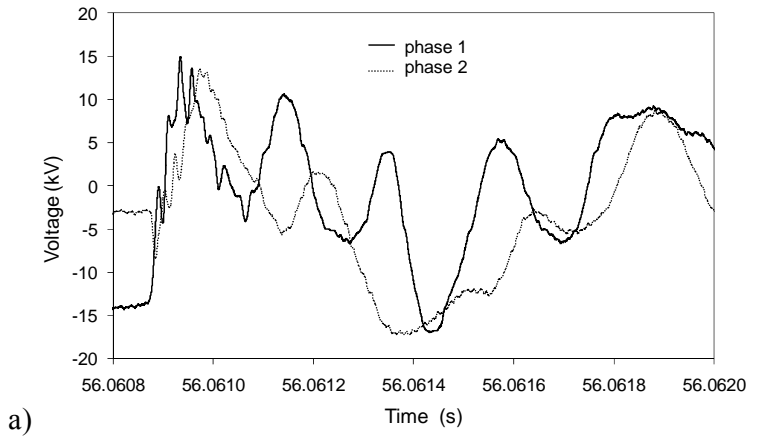

a)

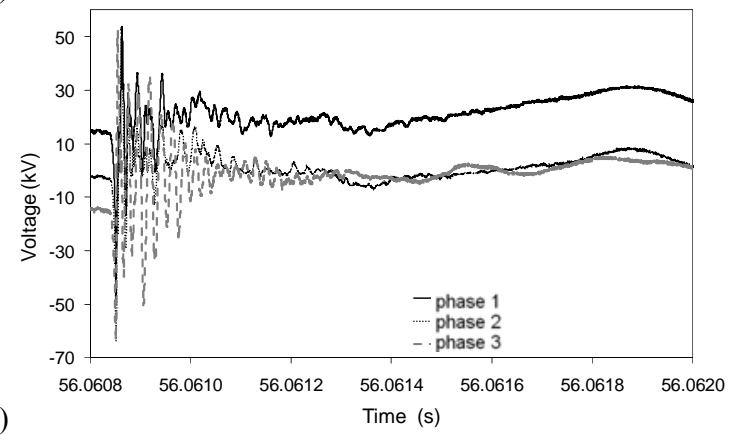

Fig. 15 Recorded voltage transients correlated with LLS event 44074: a) Unit 1, b) Unit 3. Phase 3 was not recorded at Unit 2 (moving average in a $5 \mu$ s period except for the case of Unit 3 ).

\section{CONCLUSIONS}

During the first two years of the ongoing experimental campaign on lightning-originated disturbances carried out in Italy, all the occurred flashovers, identified by the corresponding relay sequence of events, are clearly timecorrelated with LLS-detected lightning strokes.

The set of voltage transient measurements described in the paper have been obtained by using specifically developed distributed measurement units able to accurately record the waveform together with its starting time obtained by the Global Positioning System (GPS).

The recorded transients allow to analyze in detail both the effects of lightning events, e.g. the effects of different strokes in the same flash, as well as due to relay operations, e.g., those due to the delayed opening and reclosure of the different circuit breaker poles.

For the events described in this paper, the difference between the starting times of the earliest recorded voltage transients and the GPS time stamp of the corresponding LLS detected strokes lies in the range between $-89.5 \mu \mathrm{s}$ and $19.80 \mu \mathrm{s}$. The negative value indicates that the starting time of the voltage transients anticipates the time stamp of the corresponding LLS detected event. The delay of the first relay activation with respect to the time stamp of the LLS detected event is of the order of few tens of milliseconds. These delays are significantly lower than the usual value of 1 second adopted for the time correlation between lightning events and faults.
The stroke originated transients recorded by the measurement unit nearest to the stroke location appear to show the effects of the leader propagation and are mainly characterized by the effects of the faults. The earliest part of the transients recorded at distant point with respect to the stroke location shows, instead, the typical characteristics of induced voltage waveforms.

During the on-going campaign, the distributed measurement units have recorded around 2000 voltage transients that are not associated with relay operation (i.e. have not caused a flashover). Many of them are clearly due to daily capacitor bank switching and other operation maneuvers. There are also other transients (chiefly the common-mode ones) that, although not all clearly timecorrelated with one of the 569 LLS detected flashes, may be ascribed to lightning events. A Monte Carlo procedure has been proposed in [14] for the assessment of the statistical distribution of the expected overvoltages in the network due to a lightning event, based on the use of the LIOV-EMTP code [15] for the accurate calculation of the lightning induced effects. The set of the data collected during the experimental campaign appears to be useful also in order to validate and improve the proposed procedure, taking into account the uncertainties associated with the LLS data and the complexity of the distribution network.

\section{ACKNOWLEDGEMENTS}

The authors would like to warmly thank F. Rachidi and W. Schulz and for their advice throughout the development of this work. The voltage transient measurement units have been developed in collaboration with K. Yamabuki, L. Peretto and R. Tinarelli. The substantial collaboration provided by M. Parenzan, R. Vitale and their Colleagues at ENEL Distribution is gratefully acknowledged.

\section{REFERENCES}

[1] M. Darveniza, M.A. Uman, "Research into lightning protection of distribution systems II - Results from Florida field work 1978 and 1979", IEEE Trans. on Power Apparatus and Systems, Vol. PAS-103, No. 4, pp. 673682, April 1984.

[2] A. K. Mukhopadhay, "Measurement of Lightning Induced Arrester Ground Currents in a Power Distribution System Results/Lessons of Field Study", Electric Power Systems Research, Vol. 2, pp. 279-291, 1979.

[3] D.E. Parrish, D.J. Kvaltine "Lightning Faults on Distribution Lines", IEEE Trans. on Power Delivery, Vol. 4, No. 4, pp. 2179-2186, October 1989.

[4] D.E. Parrish, "Lightning-caused distribution circuit breaker operations", IEEE Trans. on Power Delivery, Vol. 6, No. 4, pp. 1395-1401, October 1991.

[5] J.G. Kappenman, "Distribution lightning fault correlation \& advanced applications of lightning data", Proc. of IEEE T\&D Conference - New Orleans, April 1999.

[6] J.G. Kappenman, M.E. Gordon and T.W. Guttormson, 
"High-Precision Location of Lightning-Caused Distribution Faults", Proc. of the IEEE Transmission and Distribution Conference and Exposition, Vol. 2, pp. 1036 1040, Oct. 28 - Nov. 2, 2001, Atlanta, U.S.A..

[7] M. Bernardi, C. Giorgi, V. Biscaglia, "Medium voltage line faults correlation with lightning events recorded with the Italian LLS system CESI-SIRF", Proc. 24th International Conference on Lightning Protection, Birmingham-UK, 1998, vol.1, pp. 187-192.

[8] J. Kosmač, V. Djurica, "Real-time fault correlator for medium voltage distribution network", 18th International Lightning Detection Conference, Helsinki, Finland, 7-9 June 2004.

[9] A. Borghetti, F. Napolitano, C.A. Nucci, M. Paolone, M. Bernardi, F. Rachidi, K. Yamabuki, "Correlation of lightning events and faults in distribution power networks: a joint research project", Proc. of the Cigré 2008 General Session, Paris France, August 24 - 29, 2008, paper C4117.

[10] D. Jiménez, M. Camargo, E. Olarte, I. Santoyo, D. Aranguren, J. Herrera, E. Pérez, H. Torres, M. Salgado, G. Guerrero, "Development of the natural laboratory for lightning induced voltages and atmospheric electricity study in La Palma - Colombia", Proc of X International Symposium on Lightning Protection, Curitiba, Brazil, 9th13th November, 2009.

[11] K. Yamabuki, A. Borghetti, F. Napolitano, C.A. Nucci, M. Paolone, L. Peretto, R. Tinarelli, M. Bernardi, R. Vitale, "A Distributed Measurement System for Correlating Faults to Lightning in Distribution Networks", Proc. of 15th International Symposium on High Voltage Engineering, Ljubljana, Slovenia, August 27-31, 2007.

[12] M. Bernardi, A. Borghetti, C. A. Nucci, F. Napolitano, M. Paolone, F. Rachidi, R. Vitale, K. Yamabuki, "LightningCorrelated Faults in Power Distribution Networks", Proc. of 2007 IEEE Lausanne Power Tech Conference, Lausanne, Switzerland, 1 - 5 July 2007.

[13] M. Bernardi, A. Borghetti, F. Napolitano, C.A. Nucci, M. Paolone, W. Schulz, "Voltage transients in a distribution network correlated with events identified by a lightning location system", Proc of X International Symposium on Lightning Protection, Curitiba, Brazil, 9th-13th November, 2009.

[14] A. Borghetti, C.A. Nucci, M. Paolone, M. Bernardi, "A Statistical Approach for Estimating the Correlation between Lightning and Faults in Power Distribution Systems", Proc. of Proc. of International Conference on Probabilistic Methods Applied to Power Systems, PMAPS 2006, Stockholm, June 11-15, 2006.

[15] C.A. Nucci, F. Rachidi, "Interaction of electromagnetic fields with electrical networks generated by lightning", Chapter 8 of the book "The Lightning Flash: Physical and Engineering Aspects", IEE Power and Energy series 34, IEE Press, 2003. 